\title{
Impact of UK Primary Care Policy Reforms on Short- Stay Unplanned Hospital Admissions for Children With Primary Care-Sensitive Conditions
}

Elizabeth Cecil, MSc ${ }^{1}$

Alex Bottle, $P b D^{1}$

Mike Sharland, $M D^{2}$

Sonia Saxena, $M D^{1}$

'Department of Primary Care and Public Health, School of Public Health, Imperial College London, United Kingdom

${ }^{2}$ Paediatric Infectious Disease Unit, St George's Hospital, University of London, United Kingdom

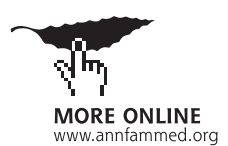

Conflicts of interest: authors report none.

\section{CORRESPONDING AUTHOR}

Elizabeth Cecil, MSc

Department of Primary Care and Public Health, Imperial College London 3rd Floor Reynolds Bldg, Charing Cross Campus

London, United Kingdom W6 8RP

e.cecil@imperial.ac.uk

\begin{abstract}
PURPOSE We aimed to assess the impact of UK primary care policy reforms implemented in April 2004 on potentially avoidable unplanned short-stay hospital admissions for children with primary care-sensitive conditions.

METHODS We conducted an interrupted time series analysis of hospital admissions for all children aged younger than 15 years in England between April 2000 and March 2012 using data from National Health Service public hospitals in England. The main outcomes were annual short-stay (<2-day) unplanned hospital admission rates for primary care-sensitive infectious and chronic conditions.
\end{abstract}

RESULTS There were 7.8 million unplanned admissions over the study period. More than one-half $(4,144,729$ of $7,831,633)$ were short-stay admissions for potentially avoidable infectious and chronic conditions. The primary care policy reforms of April 2004 were associated with an $8 \%$ increase in short-stay admission rates for chronic conditions, equivalent to 8,500 additional admissions, above the $3 \%$ annual increasing trend. Policy reforms were not associated with an increase in short-stay admission rates for infectious illness, which were increasing by $5 \%$ annually before April 2004. The proportion of primary care-referred admissions was falling before the reforms, and there were further sharp reductions in 2004.

CONCLUSIONS The introduction of primary care policy reforms coincided with an increase in short-stay admission rates for children with primary care-sensitive chronic conditions, and with more children being admitted through emergency departments. Short-stay admission rates for primary care-sensitive infectious illness increased more steadily and could be related to lowered thresholds for hospital admission.

Ann Fam Med 2015;13:214-220. doi: 10.1370/afm.1786.

\section{INTRODUCTION}

$\mathrm{P}$ ay-for-performance schemes have successfully driven improvements in care for chronic conditions in many countries. Unintended consequences of these reforms may, however, diminish primary care quality for some groups, such as children, whose care is not incentivized. In 2004, the UK National Health Service (NHS) introduced major reforms to primary care policy that aimed to improve working conditions for primary care physicians and health outcomes for patients (Table 1) ${ }^{1-3}$ The scheme focused heavily on improving chronic disease management in adults with long-term conditions, but very few $(<3 \%)$ of the health targets applied to children's care. ${ }^{4}$ Additional revisions to primary care policy in 2004 allowing primary care physicians to opt out of providing acute primary care services during evenings and weekends have reduced access, which has been associated with increased emergency department visits. ${ }^{5}$ Access to high-quality primary care is strongly associated with reduced numbers of unplanned hospital admissions for some conditions that are potentially avoidable or primary care sensitive (PCS). ${ }^{6-9}$ These changes in primary care policy are thought to have contributed to a rise in unplanned hospital admissions among children over the past decade. ${ }^{1,4,10}$ 


\section{Table 1. Major UK National Health Service Reforms in 2004}

\section{Primary care reforms}

Allowed primary care physicians greater flexibility in the services they provided, for example, opting out of responsibility for outof-hours care.

Financial incentive scheme for primary care physicians to deliver clinical and organizational care, assessed through performance target achievement (the Quality and Outcomes Framework).

\section{Emergency care reforms}

Tightening of targets so that $98 \%$ of patients wait no more than 4 hours in an emergency department from arrival to hospital admission, transfer, or discharge. ${ }^{2}$

\section{Hospital reforms}

Introduction of payment-by-results schemes changed the way a hospital was paid, from a block contract payment system for service provision to one remunerating activity, such as episodes of care.

In England, unplanned admissions of children increased between 1997 and 2006, driven by admissions associated with short stays-those characterized by minor, self-limiting conditions and lasting fewer than 2 days-which rose by $41 \% .^{7}$ Previous studies implicating primary care reforms as responsible for rises in admissions had several design flaws. First, none of these studies took into account secular trends in admission rates, linked the rises to the timing of the reforms, or controlled for the falls in long stays. Also, previous studies focusing on all short-stay admissions did not compare changes in admission rates for PCS conditions against those for comparator conditions that should not have been affected by changes in primary care. ${ }^{7}$ For example, injuries that should be seen in the hospital may result in a short stay and should not be counted as being PCS. Pediatric quality indicators in the United States and United Kingdom such as those of the Agency for Healthcare Research and Quality (AHRQ) $)^{11,12}$ have been used to measure PCS admissions ${ }^{10}$ but account for only a minority of highly frequent causes of admission among young children. ${ }^{13}$

We combined several criteria to develop a deliberately broader composite measure to capture the majority of potentially PCS childhood illnesses for which children would consult a primary care physician. Our hypothesis was that major restructuring in NHS primary care in England in 2004 adversely affected the availability of this care to children and, as a result, increased PCS short-stay unplanned hospital admissions for acute infectious and chronic conditions. We compared these trends with trends in short-stay admissions for injury as an index marker of background trends in hospital admissions and examined long-stay admissions to explore an alternative hypothesis that the burden of illness has increased over time.

\section{METHODS}

\section{Data and Definitions}

We analyzed data from Hospital Episodes Statistics, the national administrative database for hospital activity in England. ${ }^{14}$ We examined all unplanned (emergency) admissions from April 1, 2000 to March 31, 2012 among children aged younger than 15 years; an unplanned admission was an unexpected event that occurred when a child presented with an acute problem and was immediately referred for hospital treatment. Admission diagnoses are recorded in Hospital Episodes Statistics as the main reason for admission or primary diagnosis using International Classification of Diseases, 10th Revision (ICD-10) codes that can be mapped to the AHRQ Clinical Classifications Software. ${ }^{15}$

We developed broad composite indicators to identify admissions that were minor, self-limiting, and potentially PCS. Our main outcomes were short-stay admissions having a length of stay of less than 2 days and no readmission for any cause within 28 days for 2 broad groups of PCS conditions: acute infectious illness and chronic disease. We used clinical coding lists based on the AHRQ Clinical Classifications Software drawn up by a clinician expert panel (Supplemental Appendix 1, available at http://www.annfammed.org/ content/13/3/214/suppl/DC1). Discrepancies were resolved by discussion and consultation with literature to achieve consensus. Our comparator group was short-stay admissions for injury. We also examined a secondary outcome measure of a small subset of admissions for asthma, diabetes, urinary tract infection, and intestinal infection that have been used to reflect the quality of care outside of the hospital for children aged younger than 17 years and identify potentially avoidable hospitalizations among children at an area level by the AHRQ. ${ }^{11}$ We grouped admissions into 326 English local authority areas, based on patients' residential area, by sex, financial year of admission, and developmental age-group $(<1,1$ to 4 , 5 to 9 , and 10 to 14 years). Annual denominator data were Office of National Statistics midyear population estimates. ${ }^{16}$ We flagged each admission referred by a primary care physician.

To examine the effect of improved efficiency as an alternative explanation for the rise in short-stay admission rates, we assessed trends in long-stay admissions, defined as those lasting 2 days or more, which we considered to be moderate or serious and hence not PCS. We also examined same-day discharges, a subset of short-stay admissions, as a secondary outcome of minor conditions presenting to hospitals. Age- and sexspecific short- and long-stay unplanned admission rates were directly standardized to the national population of children in 2011. 


\section{Data Analysis}

To estimate changes associated with primary care policy reforms in 2004, we fitted an interrupted time series regression model of our time series for all children in England. The model had 3 main parameters: the first parameter estimated the annual trend in our outcome associated with each year from 2000 until the primary care policy reforms were introduced in April 2004, the second parameter estimated the immediate level change associated with policy change in 2004, and the third parameter estimated the trend change in our outcome associated with each year thereafter to 2011. 17,18 For each outcome, we applied a generalized estimating equation model clustering by the combination of local authority area, age, and sex with robust standard errors and an autoregressive correlation matrix. ${ }^{19,20}$ We report annual rate ratios (RRs) calculated from the parameter estimations, which represent population-averaged rates. Sensitivity analyses investigated (1) an additional change in trend seen in 2008 and (2) the confounding effect of trends in long-stay admission rates on short-stay admission rates. To investigate referral by primary care physician as the outcome, adjusted annual odds ratios (ORs) were calculated from an interrupted time series trend analysis using logistic regression. The Health and Social Care Information Centre provided ethical approval to use Hospital Episodes Statistics data for our research. We performed all analysis using Stata 11 (Stata Corp).

\section{RESULTS}

\section{Rates of Unplanned Admissions}

Between 2000 and 2011, there were 7.8 million unplanned admissions in a population of 16 million children aged younger than 15 years, of which $811,154(10 \%)$ were readmissions within 28 days of discharge. More than onehalf $(4,144,729$ of $7,831,633)$ of all unplanned admissions were potentially PCS short-stay admissions, of which $32 \%(2,492,038)$ were for acute infectious illness and $21 \%(1,652,691)$ were for chronic conditions. The AHRQ pediatric care quality indicators accounted for less than $10 \%$ of unplanned admissions and did not change significantly across the study period. The proportion of all unplanned admissions that were for a short stay increased from $66 \%$ in 2000 to $75 \%$ in 2011 (Table 2), driven by same-day discharges, which increased from $31 \%$ to $46 \%$.

Table 2. Unplanned Hospital Admissions for 2000-2001 and 2010-2011 Among Children by Age-Group and Overall

\begin{tabular}{|c|c|c|c|c|c|c|}
\hline \multirow[b]{2}{*}{ Measure } & \multicolumn{2}{|c|}{$<1$ Year } & \multicolumn{2}{|c|}{ 1-4 Years } & \multicolumn{2}{|c|}{ 5-9 Years } \\
\hline & $2000-2001$ & $2011-2012$ & $2000-2001$ & $2011-2012$ & $2000-2001$ & $2011-2012$ \\
\hline Population, No. ${ }^{a}$ & 575,000 & 679,100 & $2,405,900$ & $2,649,600$ & $3,176,900$ & $2,990,100$ \\
\hline Children admitted, No. & 115,132 & 159,486 & 163,508 & 207,573 & 94,857 & 96,232 \\
\hline Total unplanned admissions, No. & 150,694 & 215,401 & 202,161 & 267,553 & 112,772 & 118,500 \\
\hline Mean no. of admissions per child & 1.31 & 1.35 & 1.24 & 1.29 & 1.19 & 1.23 \\
\hline Length of stay, mean (SD), days & $3.0(27.0)$ & $1.5(4.5)$ & $2.1(23.7)$ & $1.0(2.8)$ & $2.4(25.0)$ & $1.2(3.2)$ \\
\hline Boys, No. (\%) & $86,823(57.6)$ & $123,384(57.3)$ & $115,818(57.3)$ & $152,984(57.2)$ & $65,481(58.1)$ & $67,636(57.1)$ \\
\hline Readmission, No. (\%) & $17,554(11.6)$ & $28,426(13.2)$ & $16,995(8.4)$ & $26,523(9.9)$ & $8,545(7.6)$ & $11,023(9.3)$ \\
\hline Same-day discharge, No. $(\%)^{c}$ & $45,595(30.3)$ & $97,531(45.3)$ & $71,376(35.3)$ & $134,516(50.3)$ & $33,424(29.6)$ & $52,827(44.6)$ \\
\hline Overnight stay, No. $(\%)^{c}$ & $45,271(30.0)$ & $55,142(25.6)$ & $74,900(37.0)$ & $81,322(30.4)$ & $43,260(38.4)$ & $37,671(31.8)$ \\
\hline$\geq 2$-day stay, No. (\%) & $58,731(39.0)$ & $56,391(26.2)$ & $55,098(27.3)$ & $46,099(17.2)$ & $35,525(31.5)$ & $24,961(21.1)$ \\
\hline \multicolumn{7}{|l|}{ Type of admission } \\
\hline Infection, No. (\%) & $83,281(55.3)$ & $104,770(48.6)$ & $101,918(50.4)$ & $154,743(57.8)$ & $37,154(32.9)$ & $40,943(34.6)$ \\
\hline Chronic, No. (\%) & $40,693(27.0)$ & $63,226(29.4)$ & $57,253(28.3)$ & $63,301(23.7)$ & $35,613(31.6)$ & $39,839(33.6)$ \\
\hline Injury, No. (\%) & $5,980(4.0)$ & $9,156(4.3)$ & $26,454(13.1)$ & $34,840(13.0)$ & $28,323(25.1)$ & $28,236(23.8)$ \\
\hline Other, No. (\%) & $20,740(13.8)$ & $38,249(17.8)$ & $16,536(8.2)$ & $14,669(5.5)$ & $11,682(10.4)$ & $9,482(8.0)$ \\
\hline \multicolumn{7}{|l|}{ AHRQ Pediatric Quality Indicators ${ }^{11}$} \\
\hline Intestinal infection, No. (\%) ${ }^{d}$ & $7,959(5.3)$ & $10,008(4.6)$ & $10,995(5.4)$ & $13,647(5.1)$ & $2,459(2.2)$ & $2,735(2.3)$ \\
\hline Urinary tract infection, No. (\%) & $3,023(2.0)$ & $5,088(2.4)$ & $2,686(1.3)$ & $3,570(1.3)$ & $1,624(1.4)$ & $1,992(1.7)$ \\
\hline Asthma, No. (\%) & $936(0.62)$ & $166(0.08)$ & $13,267(6.6)$ & $9,796(3.7)$ & $6,607(5.9)$ & $7,233(6.1)$ \\
\hline Diabetes, No. (\%) & $21(0.01)$ & $21(0.01)$ & $680(0.3)$ & $737(0.3)$ & $1,310(1.2)$ & $1,286(1.1)$ \\
\hline Referred by primary care physician, & $65,466(43.4)$ & $64,338(29.9)$ & $69,675(34.5)$ & $68,542(25.6)$ & $34,156(30.3)$ & $25,370(21.4)$ \\
\hline
\end{tabular}

AHRQ = Agency for Healthcare Research and Quality

a Office of National Statistics England midyear estimate population figures.

${ }^{\mathrm{b}}$ Readmission within 28 days of an index admission.

'Same-day discharge and overnight stay combined make short-stay admissions (those with a stay lasting $<2$ days).

${ }^{\mathrm{d}}$ Includes gastroenteritis. 
Short-stay admission rates were highest among infants and fell with age, ranging from 194 (95\% $\mathrm{CI}=193$ to 195$)$ per 1,000 children aged younger than 1 year in 2011 to $74(95 \% \mathrm{CI}=73$ to 74$), 28(95 \% \mathrm{CI}=27$ to 28 ), and $23(95 \% \mathrm{CI}=23$ to 24$)$ among children aged 1 to 4,5 to 9 , and 10 to 14 years, respectively. Owing to the large numbers of admissions, Cls generated were narrow and are not presented in full subsequently.

Infectious illness was consistently the most common reason for short-stay admissions in children aged younger than 5 years (Supplemental Appendix 2, available at http://www.annfammed.org/content/13/3/214/suppl/ DC1). Infectious illness and chronic conditions accounted for similar proportions among children aged 5 to 9 years. Because of steep rises after 2004, chronic conditions surpassed injury as the most common reason for short-stay admissions among children aged 10 to 14 years.

There were steady increases in age- and sexstandardized short-stay admission rates for infectious illness and injury over the study period, whereas rates for chronic conditions peaked in 2008 (Table 3). There were corresponding falls in long-stay admission rates (Supplemental Appendix 2).

\begin{tabular}{cccc}
\multicolumn{2}{c}{$10-14$} & Years & \multicolumn{2}{c}{ Overall } \\
\hline $2000-2001$ & $2011-20112$ & $2000-2001$ & $2011-2012$ \\
\hline $3,197,800$ & $3,067,400$ & $9,355,600$ & $9,386,200$ \\
95,601 & 91,354 & 469,098 & 554,645 \\
115,547 & 114,339 & 581,174 & 715,793 \\
1.21 & 1.25 & 1.24 & 1.29 \\
$3.2(31.5)$ & $1.6(4.8)$ & $2.6(26.5)$ & $1.3(4.0)$ \\
$65,753(56.9)$ & $61,722(54.0)$ & $333,875(57.4)$ & $405,726(56.7)$ \\
$10,032(8.7)$ & $11,631(10.2)$ & $53,126(9.1)$ & $77,603(10.8)$ \\
$27,167(23.5)$ & $43,562(38.1)$ & $177,562(30.6)$ & $328,436(45.9)$ \\
$42,333(36.6)$ & $36,608(32.0)$ & $205,764(35.4)$ & $210,743(29.4)$ \\
$45,307(39.2)$ & $30,378(26.6)$ & $194,661(33.5)$ & $157,829(22.0)$ \\
& & & \\
$29,736(25.7)$ & $28,600(25.0)$ & $252,089(43.4)$ & $329,056(46.0)$ \\
$34,142(29.5)$ & $39,366(34.4)$ & $167,701(28.9)$ & $205,732(28.7)$ \\
$31,255(27.0)$ & $29,862(26.1)$ & $92,012(15.8)$ & $102,094(14.3)$ \\
$20,414(17.7)$ & $16,511(14.4)$ & $69,372(11.9)$ & $78,911(11.0)$ \\
& & & \\
$1,145(1.0)$ & $1,306(1.1)$ & $22,558(3.9)$ & $27,696(3.9)$ \\
$943(0.8)$ & $1,162(1.0)$ & $8,276(1.4)$ & $11,812(1.7)$ \\
$4,128(3.6)$ & $4,171(3.6)$ & $24,938(4.3)$ & $21,337(3.0)$ \\
$2,614(2.3)$ & $2,775(2.4)$ & $4,625(0.8)$ & $4,819(0.7)$ \\
$32,191(27.9)$ & $21,557(18.9)$ & $201,488(34.7)$ & $179,807(25.1)$ \\
& & & \\
& & &
\end{tabular}

\section{Impact of 2004 Policy Reforms on PCS Admissions}

Estimated trends for all-cause short-stay admission rates were increasing by $4 \%$ annually $(\mathrm{RR}=1.04 ; 95 \%$ $\mathrm{CI}=1.04$ to 1.04 ) before 2004 but leveled off at 3\% per year thereafter. There was no immediate level change in 2004 (Table 4). Short-stay admission rates for infectious illness were increasing by $5 \%$ annually before April $2004(\mathrm{RR}=1.05)$. Rates leveled off in $2004(\mathrm{RR}=1.00)$ and remained at $4 \%$ annually thereafter. The annual increase in short-stay admissions for chronic conditions was $3 \%(R R=1.03)$ before 2004; an immediate increase in 2004 of $8 \%$, equivalent to 8,500 additional short-stay admissions, gave a total annual increase of $11 \%$ in 2004 ; rates continued to rise at $4 \%(R R=1.04)$ per year thereafter. These estimated parameters measuring pre-2004 trend and 2004 level change were unaffected by modeling a 2008 change in trend and adding long-stay admission rates as an explanatory variable. Short-stay admission rates for our comparator condition, injury, increased by $1 \%$ to $2 \%$ annually throughout the study period.

Long-stay admission rates fell annually by $4 \%, 4 \%$, and $2 \%$ before 2004 for infectious illness, chronic conditions, and injury, respectively (Table 4 ). There was an interruption in the decline for chronic conditions in $2004(\mathrm{RR}=1.01)$ but not for the other categories.

\section{Trends in Admissions Referred by Primary Care Physicians}

More children were referred by primary care physicians for infectious illness, $40 \%(1,122,656$ of $2,797,011)$, than for chronic conditions, $35 \%(549,800$ of $1,578,757)$. Referrals for injury were lowest at 5\% (54,889 of $1,051,991)$. The proportion of unplanned admissions referred by primary care physicians for infectious illness and chronic conditions was decreasing annually by $8 \%(\mathrm{OR}=0.92)$ and $7 \%(\mathrm{OR}=0.93)$ before the policy reforms in April 2004, dropped by a further 5\% and $6 \%$, respectively, and gradually leveled off thereafter (Table 5). The biggest reductions of $8 \%$ occurred among children aged 4 to 9 years $(\mathrm{OR}=0.92)$.

\section{DISCUSSION}

\section{Main Findings}

Our findings confirm an association between the timing of major national primary care policy reform in the United Kingdom in 2004 and increases in short-stay admission rates for PCS chronic conditions in children. The $8 \%$ rise in 2004, above the increasing trend, was equivalent to 8,500 extra short-stay admissions. These increases were accompanied by falls in admissions of children referred by a primary care physician. We did not find an immediate change in the level of 
Table 3. Standardized Short- and Long-Stay Annual Admission Rates by Year

\begin{tabular}{|c|c|c|c|c|c|c|c|c|}
\hline \multirow[b]{2}{*}{ Year } & \multicolumn{2}{|c|}{$\begin{array}{l}\text { Infectious } \\
\text { Illness }\end{array}$} & \multicolumn{2}{|c|}{$\begin{array}{c}\text { Chronic } \\
\text { Conditions }\end{array}$} & \multicolumn{2}{|c|}{ Injury } & \multicolumn{2}{|c|}{ All Cause } \\
\hline & $\begin{array}{l}\text { Short } \\
\text { Stay }\end{array}$ & $\begin{array}{l}\text { Long } \\
\text { Stay }\end{array}$ & $\begin{array}{l}\text { Short } \\
\text { Stay }\end{array}$ & $\begin{array}{l}\text { Long } \\
\text { Stay }\end{array}$ & $\begin{array}{l}\text { Short } \\
\text { Stay }\end{array}$ & $\begin{array}{l}\text { Long } \\
\text { Stay }\end{array}$ & $\begin{array}{l}\text { Short } \\
\text { Stay }\end{array}$ & $\begin{array}{l}\text { Long } \\
\text { Stay }\end{array}$ \\
\hline 2000 & 17.3 & 8.8 & 10.8 & 5.4 & 7.2 & 2.2 & 39.3 & 19.1 \\
\hline 2001 & 19.0 & 8.5 & 11.6 & 5.3 & 7.5 & 2.3 & 42.3 & 18.7 \\
\hline 2002 & 18.6 & 7.7 & 12.0 & 5.0 & 7.4 & 2.2 & 42.1 & 17.3 \\
\hline 2003 & 20.1 & 7.8 & 12.1 & 4.8 & 7.6 & 2.1 & 44.1 & 17.1 \\
\hline 2004 & 19.9 & 7.3 & 13.4 & 4.8 & 7.6 & 1.9 & 45.4 & 16.4 \\
\hline 2005 & 21.7 & 7.6 & 13.8 & 4.7 & 7.9 & 1.9 & 47.8 & 16.4 \\
\hline 2006 & 21.4 & 6.9 & 14.7 & 4.6 & 8.1 & 1.8 & 48.3 & 15.3 \\
\hline 2007 & 21.7 & 6.5 & 14.5 & 4.4 & 7.9 & 1.7 & 48.5 & 14.7 \\
\hline 2008 & 22.6 & 6.6 & 15.4 & 4.4 & 7.9 & 1.5 & 50.6 & 14.7 \\
\hline 2009 & 24.0 & 6.7 & 14.8 & 4.3 & 8.2 & 1.6 & 51.6 & 14.8 \\
\hline 2010 & 25.1 & 7.1 & 14.5 & 4.2 & 8.4 & 1.5 & 53.0 & 15.0 \\
\hline 2011 & 23.8 & 6.4 & 14.0 & 4.0 & 8.7 & 1.5 & 51.3 & 14.0 \\
\hline \multicolumn{9}{|c|}{$\begin{array}{l}\text { Notes: Directly standardized unplanned admission rates are per } 1,000 \text { children aged } 0 \text { to } 14 \text { years with no } \\
\text { readmission within } 28 \text { days. Short-stay admissions were unplanned admissions with a length of stay of less than } \\
2 \text { days. Long-stays admission were admissions with a length of stay of } 2 \text { days or more. Cls for the standardized } \\
\text { rates are very narrow (maximum span } 0.3 \text { ) and are not shown. }\end{array}$} \\
\hline
\end{tabular}

number of limitations, however. Inherent biases exist in the use of clinical codes and length of stay to derive a proxy for identifying PCS admissions. Changes in accuracy and completeness of clinical coding could have affected diagnosis categorization or referral information over the study period, ${ }^{3}$ although the use of broadly defined diagnosis groups is less likely to be affected by variations in coding of individual conditions. ${ }^{23}$ As we present only 4 years of data before policy reform, it is possible that a more important underlying trend could have been obscured $_{i}$ however, our previous report of a $41 \%$ increase in shortstay admissions over a 10 -year period (between 1997 and 2006) is comparable to our findings of a pre-2004 rate of $4 \%$ per year. ${ }^{7,8}$

short-stay admission rates for infectious illness, which were increasing annually by $5 \%$ annually well before the reforms of 2004 against a steadily rising trend for injury admissions of $1 \%$ to $2 \%$ annually.

\section{Strengths and Weaknesses in Relation to Previous Research}

Our study is the first to use interrupted time series analysis to investigate the timing of primary care policy reforms on PCS admissions among children. Our study's strengths include its size and national population coverage. National administrative admission data are a useful tool for exploring the impact of national policy change as they are not subject to bias due to regional variations of individual clinicians. ${ }^{21}$ Our definition of a PCS admission was deliberately broad and captured a wide spectrum of potentially avoidable admissions. Pediatric indicator sets adopted by previous studies $^{10,22}$ accounted for only selected infectious and chronic conditions that, together, explained less than $30 \%$ of short-stay admissions in children. By contrast, in our study, the 10 most frequent causes for admission for potentially avoidable admissions for PCS infectious and chronic conditions accounted for more than $70 \%$ of short-stay admissions (Supplemental Appendix 3, http:// www.annfammed.org/content/13/3/214/suppl/DC1).

Our broader composite indicators for acute and chronic PCS conditions may be useful for future research to monitor the impact of primary care on potentially avoidable admissions among children.

We acknowledge that our results are subject to a
Our findings may be confounded by concurrent health policy and service changes in hospital care around 2004 (Table 1). UK government performance targets introduced in 2000 were tightened in 2004 whereby emergency departments incurred heavy penalties if patients waited longer than 4 hours. In response, many hospitals introduced short-stay admission facilities for assessment and observation, which may explain increases in same-day discharge rates but not differing trends across diagnosis categories. ${ }^{2,10,24}$ Financial tariff schemes for hospital activities including admissions were introduced starting in 2003, but there was only limited evidence of "gaming" by a small number of hospital trusts to increase payments. ${ }^{3,25}$ Shorter length of stay is associated with improved efficiency in hospitals when offset by a reduction in longer-stay admissions of 2 days or more; we adjusted for changes in long-stay admission rates and found increased efficiency does not explain the increases in short-stay admissions.

\section{Implications and Future Research}

Although we cannot infer causation from our findings, the magnitude of an $11 \%$ increase in short-stay admissions for chronic disease lends weight to speculation from previous reports that such admissions may increase when primary care provision is withdrawn. ${ }^{10}$ Our findings that short-stay admission rates among children with chronic conditions changed immediately in 2004 and are now surpassing other causes of admission in older children are particularly concerning. This development may indicate an adverse impact of 
Table 4. Annual Rate Ratios Estimating Trends Before and After 2004 Primary Care Policy Reforms in Admission Rates

\begin{tabular}{|c|c|c|c|c|}
\hline \multirow[b]{2}{*}{ Admission Type } & \multicolumn{2}{|c|}{$\begin{array}{c}\text { Short-Stay } \\
\text { Admission Rates }^{a}\end{array}$} & \multicolumn{2}{|c|}{$\begin{array}{c}\text { Long-Stay } \\
\text { Admission Rates }\end{array}$} \\
\hline & $\begin{array}{l}\text { \% Annual } \\
\text { Change }\end{array}$ & $\begin{array}{l}\text { Rate Ratioc } \\
(95 \% \mathrm{Cl})\end{array}$ & $\begin{array}{l}\text { \% Annual } \\
\text { Change }\end{array}$ & $\begin{array}{l}\text { Rate Ratioc } \\
(95 \% \mathrm{Cl})\end{array}$ \\
\hline \multicolumn{5}{|l|}{ Infectious illness } \\
\hline Trend pre 2004 & 5 & $1.05(1.05-1.05)$ & -4 & $0.96(0.96-0.96)$ \\
\hline Change 2003 to 2004 & 0 & $1.00(1.00-1.00)$ & -6 & $0.94(0.94-0.95)$ \\
\hline Trend post 2004 & 3 & $1.03(1.03-1.03)$ & -1 & 0.99 (0.99-0.99) \\
\hline \multicolumn{5}{|l|}{ Chronic conditions } \\
\hline Trend pre 2004 & 3 & $1.03(1.03-1.04)$ & -4 & $0.96(0.96-0.96)$ \\
\hline Change 2003 to 2004 & 11 & $1.11(1.11-1.12)$ & 1 & $1.01(1.01-1.02)$ \\
\hline Trend post 2004 & 1 & $1.01(1.01-1.01)$ & -1 & 0.99 (0.98-0.99) \\
\hline \multicolumn{5}{|l|}{ Injury } \\
\hline Trend pre 2004 & 1 & $1.01(1.01-1.02)$ & -2 & 0.98 (0.98-0.99) \\
\hline Change 2003 to 2004 & 0 & $1.00(0.99-1.01)$ & -7 & $0.93(0.91-0.95)$ \\
\hline Trend post 2004 & 2 & $1.02(1.01-1.03)$ & -4 & $0.96(0.95-0.97)$ \\
\hline \multicolumn{5}{|l|}{ All cause } \\
\hline Trend pre 2004 & 4 & $1.04(1.04-1.04)$ & -4 & $0.96(0.96-0.97)$ \\
\hline Change 2003 to 2004 & 4 & $1.04(1.03-1.04)$ & -3 & $0.97(0.97-0.97)$ \\
\hline Trend post 2004 & 2 & $1.02(1.02-1.02)$ & -2 & $0.98(0.98-0.98)$ \\
\hline \multicolumn{5}{|c|}{$\begin{array}{l}\text { Notes: Interrupted time series regression models were individually constructed for short- and long-stay admis- } \\
\text { sions in } 3 \text { diagnosis categories. Data are for } 326 \text { local authority areas over } 12 \text { years (2000-2001 through 2011- } \\
\text { 2012) among children aged younger than } 15 \text { years. }\end{array}$} \\
\hline \multicolumn{5}{|c|}{$\begin{array}{l}\text { a Unplanned admissions with a length of stay of less than } 2 \text { days. } \\
\text { b Unplanned admissions with a length of stay of } 2 \text { days or more. } \\
\text { 'Calculated from model parameter coefficients. }\end{array}$} \\
\hline
\end{tabular}

widened inequalities as a result of unintended consequences for children and other groups. ${ }^{29,30}$ Continuity of care, important in building a parent-physician relationship and preventing the use of emergency health services, also reportedly suffered with the introduction of pay for performance. ${ }^{31-33}$ Evidence of the impact of pay for performance in the United Kingdom on children's access to primary care physicians is limited, but primary care consultation rates rose between 1995 and 2006 in all age-groups except for children aged 5 to 14 years. ${ }^{34}$

We did not find a direct relationship for rising admissions for infectious illness in children, which predated the primary care policy reforms. Infectious illness is common among young children and particularly sensitive to the availability of out-of-hours care. Steep increases before 2004 may reflect gradual changes in out-ofhours primary care provision from

Table 5. Annual Odds Ratios Estimating Trends in Primary Care Physician-Referred Admissions Before and After 2004 Primary Care Policy Reforms

\begin{tabular}{|c|c|c|}
\hline Admission Type & $\begin{array}{l}\% \text { Annual } \\
\text { Change }\end{array}$ & $\begin{array}{l}\text { Odds Ratio } \\
(95 \% \mathrm{Cl})\end{array}$ \\
\hline \multicolumn{3}{|l|}{ Infectious illness } \\
\hline Trend pre 2004 & -8 & $0.92(0.92-0.92)$ \\
\hline Change 2003 to 2004 & -12 & $0.88(0.86-0.89)$ \\
\hline Trend post 2004 & -2 & 0.98 (0.98-0.99) \\
\hline \multicolumn{3}{|l|}{ Chronic conditions } \\
\hline Trend pre 2004 & -7 & $0.93(0.93-0.93)$ \\
\hline Change 2003 to 2004 & -13 & $0.87(0.86-0.89)$ \\
\hline Trend post 2004 & -3 & $0.97(0.96-0.98)$ \\
\hline \multicolumn{3}{|l|}{ Injury } \\
\hline Trend pre 2004 & -5 & $0.95(0.94-0.96)$ \\
\hline Change 2003 to 2004 & -10 & $0.90(0.85-0.95)$ \\
\hline Trend post 2004 & -1 & $0.99(0.96-1.02)$ \\
\hline \multicolumn{3}{|c|}{$\begin{array}{l}\text { Note: Data are for } 12 \text { years (2000-2001 through 2011-2012) among childrer } \\
\text { younger than } 15 \text { years. }\end{array}$} \\
\hline \multicolumn{3}{|c|}{$\begin{array}{l}\text { a Annual odds ratios were estimated from the model parameter coefficients, } \\
\text { which were adjusted for age and sex. }\end{array}$} \\
\hline
\end{tabular}

financial incentive schemes focusing on chronic conditions in adults. ${ }^{26}$ The success of the scheme on improving quality of care and clinical outcomes has been questioned, ${ }_{1}^{27,28}$ and there has been concern that it has
$2000^{35}$; by 2004 , more than $95 \%$ of primary care physicians had opted out of this care provision nationally. Certainly, the large increases in admissions with sameday discharge may reflect a trend in emergency departments toward hospitalizing children for observation. 10,36

The expansion in primary care-based activity as a result of reforms has meant that primary care physicians are struggling to maintain their existing workload, ${ }^{37}$ and existing health care provision in England is not sufficient to contain childhood illness in the community. Concerns about rising emergency department visits and short-stay admissions have sparked calls for a reversal of policy reform, suggesting UK primary care physicians should extend access to primary care outside of core hours, and controversial pilot schemes for 24/7 care are now proposed in many areas. ${ }^{38}$ Such changes, however, have huge implications for the primary care physician workforce and UK health system budgets. We recommend further research to model clinical and costeffectiveness and survey parental attitudes to weigh best options for avoiding admissions in children.

To read or post commentaries in response to this article, see it online at http://www.annfammed.org/content/13/3/214.

Key words: pay for performance; unplanned admissions; short-stay admissions; children; out-of-hours health care; trends; primary care 
Submitted August 22, 2014; submitted, revised, March 3, 2015; accepted March 19, 2015.

Funding support: E.C. and S.S. are funded by National Institute for Health Research (Career Development Fellowship CDF-2011-04048). This article presents independent research commissioned by the National Institute for Health Research (NIHR).

Disclaimer: The views expressed in this publication are those of the author(s) and not necessarily those of the NHS, the NIHR, or the Department of Health.

Supplementary materials: Available at http://www.AnnFamMed. org/content/13/3/214/suppl/DC1/.

\section{References}

1. Department of Health (United Kingdom). Investing in General Practice: The New General Medical Services Contract. London, England: Department of Health; 2003.

2. Department of Health. The NHS Plan: A Plan for Investment, a Plan for Reform. London, England: Department of Health; 2000.

3. Audit Commission (United Kingdom). Improving coding, costing and commissioning: Annual report on the Payment by Results data assurance programme 2010/11. http://www.audit-commission. gov.uk/2011/09/improving-coding-costing-and-commissioningannual-report-on-the-payment-by-results-data-assuranceprogramme-201011/. Published Sep 22, 2011. Accessed Apr 7, 2015.

4. Roland M, Campbell S. Successes and failures of pay for performance in the United Kingdom. N Engl J Med. 2014;370(20):1944-1949.

5. Cowling TE, Cecil EV, Soljak MA, et al. Access to primary care and visits to emergency departments in England: a cross-sectional, population-based study. PLoS One. 2013;8(6):e66699.

6. Starfield B, Shi L, Macinko J. Contribution of primary care to health systems and health. Milbank Q. 2005;83(3):457-502.

7. Saxena S, Bottle A, Gilbert R, Sharland M. Increasing short-stay unplanned hospital admissions among children in England; time trends analysis '97-'06. PLoS One. 2009;4(10):e7484.

8. Huntley $A$, Lasserson $D$, Wye $L$, et al. Which features of primary care affect unscheduled secondary care use? A systematic review. BMJ Open. 2014;4(5):e004746.

9. Saxena S, Francis N, Sharland M. Primary care of children: the unique role of GPs. Br J Gen Pract. 2012;62(600):340-341.

10. Gill PJ, Goldacre MJ, Mant D, et al. Increase in emergency admissions to hospital for children aged under 15 in England, 1999-2010: national database analysis. Arch Dis Child. 2013;98(5):328-334.

11. Agency for Healthcare Research and Quality. Pediatric Quality Indicators. http://qualityindicators.ahrq.gov/modules/pdi_resources. aspx. Accessed Apr 7, 2015.

12. Health and Social Care Information Centre. NHS Outcomes Framework Indicators. http://www.hscic.gov.uk/nhsof. Accessed Apr 7, 2015.

13. Friedman B, Berdahl T, Simpson LA, McCormick MC, Owens PL, Andrews R, et al. Annual Report on Health Care for Children and Youth in the United States: Focus on Trends in Hospital Use and Quality. Acad Pediatr. 2011;11(4):263-279.

14. Health and Social Care Information Centre. Hospital Episode Statistics. http://www.hscic.gov.uk/hes. Accessed Apr 7, 2015.

15. Agency for Healthcare Research and Quality. Clinical Classifications Software. http://www.ahrq.gov/research/data/hcup/icd10usrgd.html. Accessed Apr 7, 2015.

16. Office for National Statistics. Population Estimates. http://www.ons. gov.uk/ons/taxonomy/index.html?nscl = Population+Estimates + by+ Age+and+Sex\#tab-data-tables. Accessed Apr 7, 2015.

17. Wagner AK, Soumerai SB, Zhang F, Ross-Degnan D. Segmented regression analysis of interrupted time series studies in medication use research. J Clin Pharm Ther. 2002;27(4):299-309.
18. Alshamsan R, Lee JT, Majeed A, Netuveli G, Millett C. Effect of a UK pay-for-performance program on ethnic disparities in diabetes outcomes: interrupted time series analysis. Ann Fam Med. 2012; 10(3):228-234.

19. Zeger SL, Liang KY. Longitudinal data analysis for discrete and continuous outcomes. Biometrics. 1986;42(1):121-130.

20. Fretheim A, Soumerai SB, Zhang F, Oxman AD, Ross-Degnan D. Interrupted time-series analysis yielded an effect estimate concordant with the cluster-randomized controlled trial result. J Clin Epidemiol. 2013;66(8):883-887.

21. Goodacre S. Hospital admissions with head injury following publication of NICE guidance. Emerg Med J. 2008;25(9):556-557.

22. Torio CM, Elixhauser A, Andrews RM. Trends in Potentially Preventable Hospital Admissions among Adults and Children, 2005-2010: Statistical Brief No. 151. Rockville, MD: Agency for Health Care Policy and Research; March 2013.

23. Dixon J, Sanderson C, Elliott P, Walls P, Jones J, Petticrew M. Assessment of the reproducibility of clinical coding in routinely collected hospital activity data: a study in two hospitals. J Public Health Med. 1998;20(1):63-69.

24. Scribano PV, Wiley JF II, Platt K. Use of an observation unit by a pediatric emergency department for common pediatric illnesses. Pediatr Emerg Care. 2001;17(5):321-323.

25. Blunt I, Bardsley M, Dixon J. Trends in Emergency Admissions in England 2004-2009. http://www.nuffieldtrust.org.uk/publications/trendsemergency-admissions-england-2004-2009. Published Jul 5, 2010. Accessed Apr 7, 2015.

26. Kyle RG, Kukanova M, Campbell M, Wolfe I, Powell P, Callery P. Childhood disadvantage and emergency admission rates for common presentations in London: an exploratory analysis. Arch Dis Child. 2011;96(3):221-226.

27. Heath I, Hippisley-Cox J, Smeeth L. Measuring performance and missing the point? BMJ. 2007;335(7629):1075-1076.

28. Gillam SJ, Siriwardena AN, Steel N. Pay-for-performance in the United Kingdom: impact of the quality and outcomes framework-a systematic review. Ann Fam Med. 2012;10(5):461-468.

29. Campbell SM, Reeves D, Kontopantelis E, Sibbald B, Roland M. Effects of pay for performance on the quality of primary care in England. N Engl J Med. 2009;361(4):368-378.

30. Chien AT, Dudley RA. Pay-for-performance in pediatrics: proceed with caution. Pediatrics. 2007;120(1):186-188.

31. Gill JM, Mainous AG III, Nsereko M. The effect of continuity of care on emergency department use. Arch Fam Med. 2000;9(4):333-338.

32. Campbell SM, Kontopantelis E, Reeves $D$, et al. Changes in patient experiences of primary care during health service reforms in England between 2003 and 2007. Ann Fam Med. 2010;8(6):499-506.

33. Mainous AG, Baker R, Love MM, Gray DP, Gill JM. Continuity of care and trust in one's physician: evidence from primary care in the United States and the United Kingdom. Fam Med. 2001;33(1):22-27.

34. Hippisley-Cox J, Fenty J, Heaps M. Trends in Consultation Rates in General Practice 1995 to 2006: Analysis of the QRESEARCH database. Final Report to the Information Centre and Department of Health. http://www.qresearch.org/Public_Documents/Trends\%20 in $\% 20$ consultation $\% 20$ rates $\% 20$ in $\% 20$ general\%20practice $\% 20$ 1995\%20to\%202006.pdf. Published Jul 2007. Accessed Apr 7, 2015.

35. Department of Health (United Kingdom). Raising Standards for Patients, New Partnerships in Out-of-Hours Care. http://www.out-ofhours.info/downloads/oohreview.pdf. Published Oct 2000. Accessed Apr 7, 2015.

36. Simmonds RL, Shaw A, Purdy S. Factors influencing professional decision making on unplanned hospital admission: a qualitative study. Br J Gen Pract. 2012;62(604):e750-e756.

37. Gerada C, Riley B. The 2022 GP: our profession, our patients, our future. Br J Gen Pract. 2012;62(604):566-567.

38. Kingsland JP, Swinyard PW. Should general practices open for longer? BMJ. 2013;347:f6832. 